\title{
Formation of Nanocrystalline Zeolites in Geopolymer Gels
}

\author{
J. L. Bell,* P. Sarin* and W. M. Kriven* \\ * Department of Materials Science and Engineering, University of Illinois at Urbana Champaign, \\ Urbana, IL 61801
}

"Geopolymers" are aluminosilicate network structures formed when an aluminosilicate phase is added to either an alkaline silicate or alkaline based solution [1]. For example, when metakaolin is mixed with a sodium or potassium based silicate solution, a geopolymeric gel phase is formed, which hardens in less than $4 \mathrm{~h}$ even at low temperatures $\left(\approx 40-50^{\circ} \mathrm{C}\right)$. Metakaolin based geopolymers generally have a Si:Al molar ratio in the range of approximately 2-4, where the lower bound is determined by metakaolin, while the upper bound is limited by the solubility of silica in the alkaline silica solution. Processing of geopolymers is analogous to that of low silica zeolite in that both require a high $\mathrm{pH}$ concentrated alkali solution, and can be reacted below $150^{\circ} \mathrm{C}$ [2]. For instance, zeolite A was synthesized by addition of metakaolin to a dilute sodium solution of sodium hydroxide [3]. In contrast, geopolymers are prepared using very concentrated alkali solutions and require much shorter processing times.

Geopolymer gels, although x-ray amorphous, may contain nanocrystalline zeolite compacted in an amorphous gel phase [4]. In order to test this hypothesis, a series of geopolymeric compositions were prepared (see Table I) and examined using high resolution transmission electron microscopy (HRTEM), scanning electron microscopy (SEM), and synchotron x-ray diffraction (XRD). Of the nine compositions examined, only samples with the composition $2 \mathrm{SiO}_{2}: \mathrm{Al}_{2} \mathrm{O}_{3}: \mathrm{Na}_{2} \mathrm{O}$ (sample 9 in Table 1) contained zeolite crystals. HRTEM results confirmed the presence of crystals in the size range of 6-10nm (see Fig. 1a). The high resolution structure of samples 1-8 contained nanometer sized particulate features and pores as shown in Fig. 1b, which is typical of amorphous geopolymers. Subsequent synchrotron X-ray diffraction (XRD) results confirmed that sample 9 crystallized into Zeolite A (ICDD-JCPDF \# 01-073-2340). Whole pattern fitting analysis of XRD data showed that the sample was comprised of $96 \mathrm{wt} \%$ amorphous phase and $4 \mathrm{wt} \%$ crystalline Zeolite A. Therefore, the concentrated nature of geopolymer gels permitted only small amount of zeolite crystallization.

\section{References}

[1] J. Davidovits, Journal of Thermal Analysis, 35(2) (1989) 429

[2] J. Davidovits, First International Conference on Alkaline Cements and Concretes, Kiev State Technical University, Kiev, Ukraine (1994) 131

[3] P. Dutta et al., J. Phys. Chem., 90 (1986) 2331

[4] J. Provis et al., Chem. of Materials, 17 (2005) 3075

[5] This research was supported by the Air Force Office of Scientific Research Contract\# FA955004-C-0063. The help from Dr. J. G. Wen is gratefully acknowledged. Microscopy analysis was conducted at the Center for Microanalysis of Materials, University of Illinois, which is partially supported by the U.S. Department of Energy under grant DEFG02-91-ER45439. Use of the National Synchrotron Light Source, Brookhaven National Laboratory, was supported by the U.S. Department of Energy, Office of Science, Office of Basic Energy Sciences, under Contract No. DE-AC02-98CH10886. 
TABLE 1. Geopolymer Compositions of Interest

\begin{tabular}{|c|c|c|c|}
\hline \multirow{2}{*}{$\begin{array}{c}\text { Alkali Molar } \% \\
\left(\% \mathrm{Na}_{2} \mathrm{O}, \% \mathrm{~K}_{2} \mathrm{O}\right)\end{array}$} & \multicolumn{3}{|c|}{ Silica to Alumina Molar Oxide Ratio $\left(\mathrm{SiO}_{2}: \mathrm{Al}_{2} \mathrm{O}_{3}\right)$} \\
\cline { 2 - 4 } & 4 & 3 & 2 \\
\hline 100,0 & Sample 1 & Sample 4 & Sample 7 \\
\hline 50,50 & Sample 2 & Sample 5 & Sample 8 \\
\hline 0,100 & Sample 3 & Sample 6 & Sample 9 \\
\hline
\end{tabular}

*Water used corresponded to $\mathrm{M}_{2} \mathrm{O}: \mathrm{H}_{2} \mathrm{O}=10$ where $\mathrm{M}=\mathrm{Na}+\mathrm{K}$. Curing conditions were $50^{\circ} \mathrm{C}$ for $48 \mathrm{~h}$.

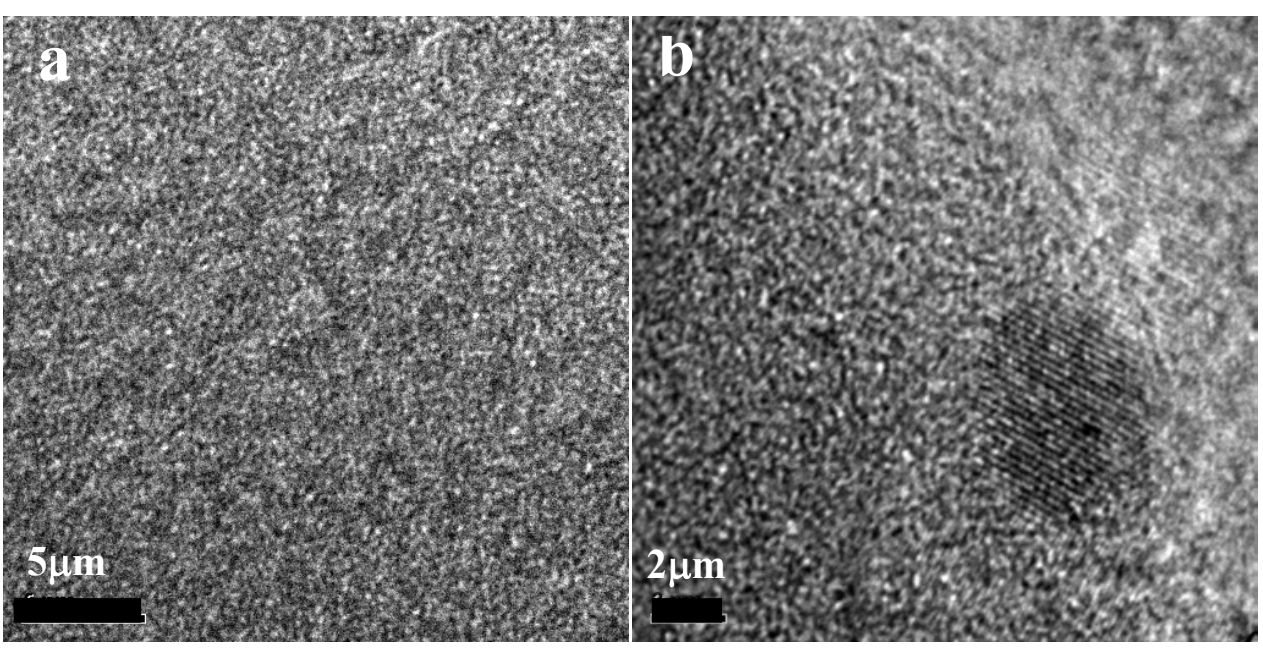

FIG. 1. HRTEM structure for (a) sample 1 and (b) sample 9. Samples 1-8 had a similar structure to that of (a). Nanocrystalline zeolite regions were found in sample 9, as shown in (b). Analysis was done using a JEOL 2010F (S)TEM. Samples were prepared by grinding with a mortar and pestle and depositing on a holey carbon grid.
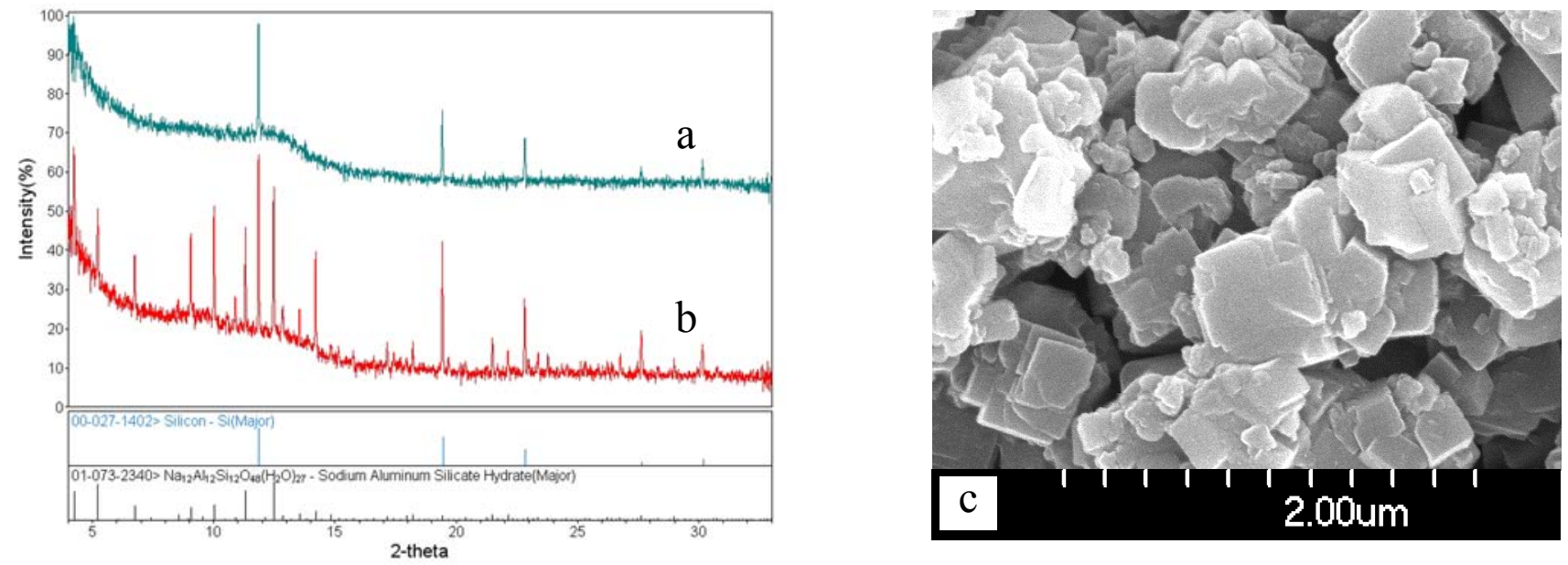

FIG. 2. Synchrotron X-ray diffraction results, using a wavelength of $0.648625 \AA$, for (a) sample 3 , and (b) sample 9. For both samples $10 \mathrm{wt} \%$ silicon standard from NIST (SRM 640b) was added prior to measurements. Samples 1-8 were all amorphous with an amorphous peak at $\approx 12^{\circ} 2$-theta, as shown for case (a) above. Sample 9 crystallized into Zeolite A as illustrated in (b). The SEM micrograph in (c) shows cubic zeolite crystallites in the 1-2 $\mu \mathrm{m}$ size range observed in sample 9. 